\title{
Effect of Breakwaters on Reduction of Fatality Ratio during the 2011 Great East Japan Earthquake and Tsunami
}

\author{
Panon LATCHAROTE ${ }^{1}$, Anawat SUPPASRI ${ }^{2}$, Natsuki HASEKAWA ${ }^{3}$, \\ Hiroshi TAKAGI ${ }^{4}$ and Fumihiko IMAMURA ${ }^{5}$ \\ ${ }^{1}$ Member of JSCE, Postdoctoral Researcher, International Research Institute of Disaster Science, Tohoku University \\ (468-1 Aramaki-aza Aoba, Aoba-ku, Sendai 980-0845, Japan) \\ E-mail: panon@irides.tohoku.ac.jp \\ 2 Member of JSCE, Associate Professor, International Research Institute of Disaster Science, Tohoku University \\ (468-1 Aramaki-aza Aoba, Aoba-ku, Sendai 980-0845, Japan) \\ E-mail: suppasri@irides.tohoku.ac.jp \\ 3 Member of JSCE, Master Student, International Research Institute of Disaster Science, Tohoku University \\ (468-1 Aramaki-aza Aoba, Aoba-ku, Sendai 980-0845, Japan) \\ E-mail: natsuki.hasegawa.s8@dc.tohoku.ac.jp \\ ${ }^{4}$ Member of JSCE, Associate Professor, Graduate School of Science and Engineering, Tokyo Institute of Technology \\ (2-12-1 Ookayama, Meguro-ku, Tokyo 152-8550, Japan) \\ E-mail: takagi@ide.titech.ac.jp \\ ${ }^{5}$ Member of JSCE, Professor, International Research Institute of Disaster Science, Tohoku University \\ (468-1 Aramaki-aza Aoba, Aoba-ku, Sendai 980-0845, Japan) \\ E-mail: imamura@irides.tohoku.ac.jp
}

\begin{abstract}
Based on lesson learned from the 2011 Great East Japan tsunami, tsunami height is the most influential factor on fatality of people living in coastal area. This paper proposes effect of breakwaters on fatality ratio of people and investigate a reduction of fatality ratio due to the existence of breakwaters. For preliminary study, 24 fishery ports equipped with breakwaters were selected to study how breakwaters affect to loss of fatality ratio along Sanriku ria-coast from Taro to Ishinomaki. The port area behind breakwaters was considered to calculate fatality ratio from number of fatality divided by total number of people and then fatality ratio was linearly correlated with observed tsunami height. In order to estimate fatality ratio in case of ports without breakwaters, simulated tsunami height was calculated by TUNAMI modeling with nesting grids of $1350 \mathrm{~m}, 450 \mathrm{~m}, 150 \mathrm{~m}$, and $50 \mathrm{~m}$. For the overall image, breakwaters could reduce fatality ratio of people in the port area with a percentage of reduction approximately $30 \%$. Considering the effect of breakwaters at each port, it was found that fatality ratio of ports equipped with breakwaters is less than those in case of ports without breakwaters for most of ports. In addition to these 24 ports, 18 additional ports equipped with breakwaters were conducted to additional study and compared with 24 ports having no breakwaters. For the overall image, the percentage of reduction became $1 \%$, which is much lower than the reduction in the preliminary study. Focusing on each port, two third of them still provided the reduction of fatality ratio.
\end{abstract}

Key Words: 2011 Great East Japan tsunami, fatality ratio, breakwaters, tsunami height, loss reduction

\section{INTRODUCTION}

The 2011 Great East Japan tsunami caused a wide range of devastating tsunami with maximum tsunami height of $40 \mathrm{~m}$ and 19,000 casualties along the Tohoku coast ${ }^{1}$. Difference in coastal topography, such as Sanriku ria-coast and Sendai plain, leads to a significant difference in tsunami and evacuation characteristics. Considering influential factors on fatality of people, tsunami characteristics is a factor of tsunami height and tsunami arrival time, while evacuation characteristics is a factor of experience, preparedness, age, gender, and occupation. From past studies, a relationship between fatality ratio and influential factors was proposed based on the surveyed data after the 2011 Great East Japan tsunami and it was found that tsunami height is a major influence on fatality ratio ${ }^{2}$. After tsunami, breakwaters are important to conduct port operations for immediate disaster relief. However, the major function of 
breakwaters is not designed for loss reduction from tsunami. Therefore, this study aims to propose effect of breakwaters on fatality ratio of people living behind ports equipped with breakwaters, which could reduce tsunami intensity during the 2011 tsunami. In addition, this study investigates a reduction of fatality ratio due to the existence of breakwaters.

\section{DATA AND METHOD}

\section{(1) Breakwater and fatality data}

The locations of ports equipped with breakwaters in Fig. 1 were selected to study how breakwaters affect to a reduction of fatality ratio for people living behind ports. The data of breakwaters from 24 ports ${ }^{3)}$ with available data of fatality ratio and observed tsunami height were collected along Sanriku ria-coast from Taro to Ishinomaki. The breakwater data contains breakwater location, dimension and damage, including tsunami height at breakwater ${ }^{3)}$. As can be seen in Fig. 1, the residential area behind the fishery ports was considered to calculate fatality ratio (FR) from number of fatality (D) divided by total number of people $(\mathrm{N})$ in this port area. For each port area, fatality ratio was investigated using disaster victim database collected by Reconstruction Assistance Research Archive, University of Tokyo. In this study, fatality ratio was linearly correlated with observed tsunami height measured by the 2011 Tohoku Earthquake Tsunami Joint Survey (TTJS) Group.

\section{(2) Numerical simulation and validation}

In order to estimate fatality ratio in case of ports without breakwaters, simulated tsunami height was calculated by TUNAMI ${ }^{9), 10)}$ modeling with nesting grids of $1350 \mathrm{~m}, 450 \mathrm{~m}, 150 \mathrm{~m}$, and $50 \mathrm{~m}$. The finest grid $(50 \mathrm{~m})$ of bathymetry and topography data does not include breakwaters. Numerical tsunami simulation was performed to collect tsunami height at port locations without breakwaters inside the finest grid. Initial seafloor deformation was calculated by a rectangular fault model $^{4)}$ using the fault parameters of the 2011 Great East Japan earthquake with 55-subfault model ${ }^{5)}$.

Validation of the simulation was performed using the Root Mean Square Error (RMSE), and the parameters $K$ and $\kappa$ proposed by Aida (1978) for reproduction of tsunami height in this study. The simulated tsunami height $\left(h_{s}\right)$ was validated using observed tsunami height $\left(h_{0}\right)$ measured by TTJS of 33 locations of port having no effective breakwaters against tsunami shown in Fig. 2. The value of RMSE are $1.07 \mathrm{~m}$. The values of $K$ and $\kappa$ are 1.05 and 1.12, respectively. The Japan Society of Civil Engineering (JSCE) suggests that $0.95<K<1.05$ and $\kappa<1.45$ is recommended as "Good agreement" in the evaluation of tsunami source and propagation model. The $\kappa$ value can satisfy the standard, whereas the $K$ value is somewhat acceptable equally to the limited value of the standard. Therefore, this numerical simulation is valid and reliable for reproduction of tsunami height in case of ports without breakwaters.
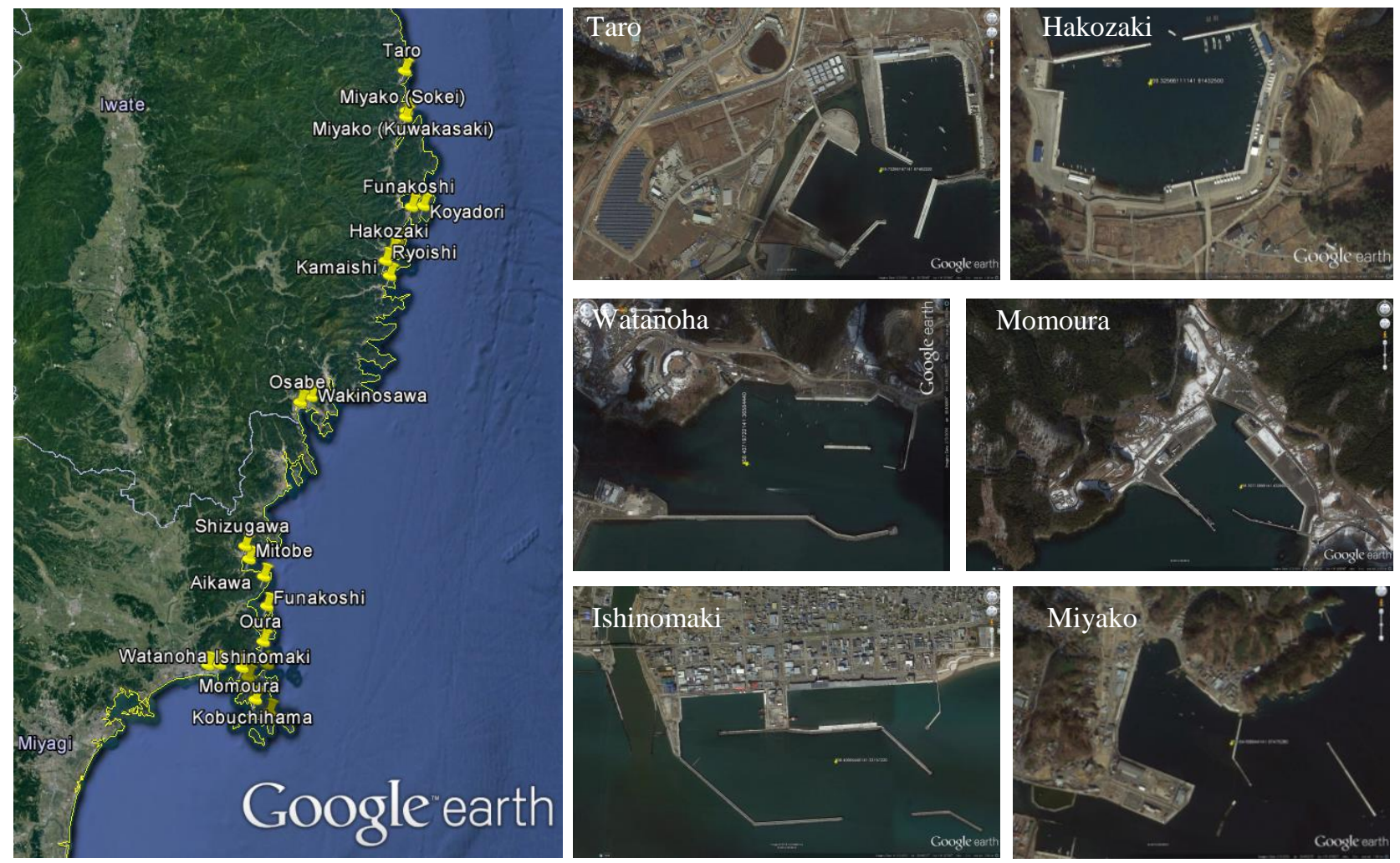

Fig.1 Location of investigated ports equipped with breakwaters and satellite images of port area (Google Earth). 


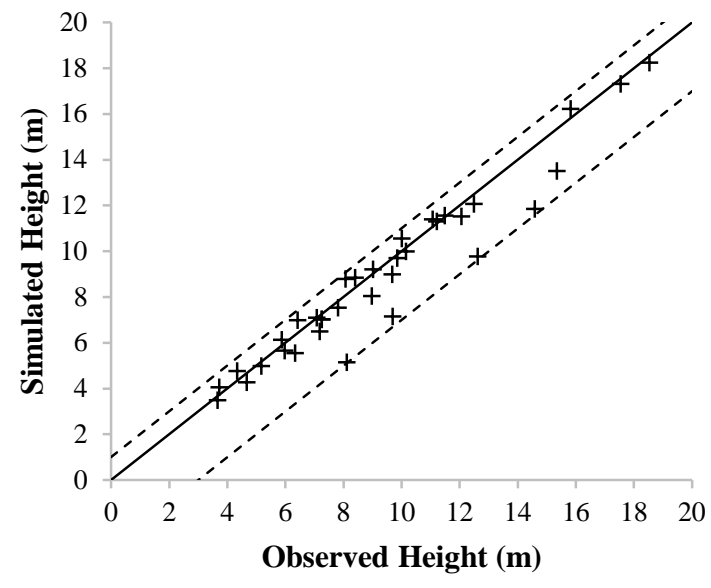

Fig.2 Comparison of simulated and observed tsunami height at each port having no breakwaters.

\section{(3) Linear regression analysis}

The estimated fatality ratio in case of ports without breakwaters was predicted by means of the simulated tsunami height $\left(\mathrm{h}_{\mathrm{s}}\right)$ and a general estimating equation developed from 13 city data ${ }^{2)}$ by linear regression analysis shown in Fig. 3. For this preliminary study, these 13 cities are a large-scale area, not particular in a port area. Therefore, the estimation of fatality ratio in case of ports without breakwaters would be less accuracy because of such a simple assumption. However, more advanced assumption was used for the estimation of fatality ratio in additional study. For fatality ratio and observed tsunami height $\left(h_{0}\right)$ of ports equipped with breakwaters, linear regression analysis was performed to develop a relationship between fatality ratio and tsunami height shown in Fig. 4. The regression lines in Fig. 3 and Fig. 4 represent the linear estimated fatality ratio at different tsunami height for overall comparison. The estimated fatality ratio at each location in case of ports without breakwaters was calculated by means of the simulated tsunami height and the general estimating equation. The differences $(\Delta \mathrm{FR})$ between the estimated fatality ratio and the surveyed data of fatality ratio (FR) at each port are shown in Table 1.

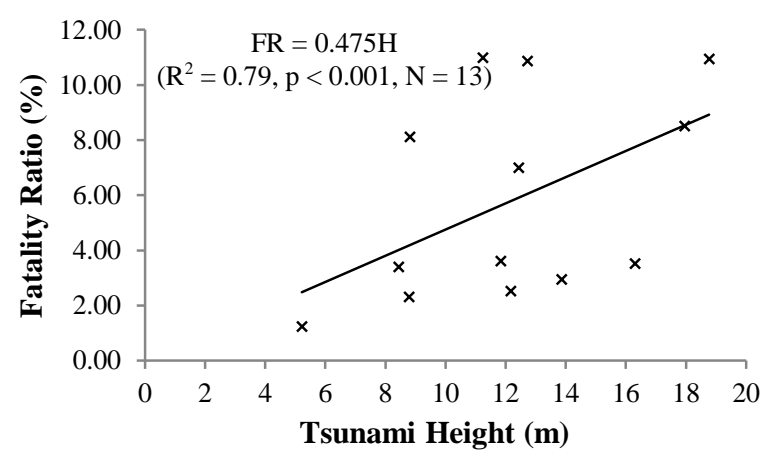

Fig.3 Linear regression analyis from 13 city data ${ }^{2)}$.

\section{RESULTS AND DISCUSSIONS}

\section{(1) Preliminary results}

Fig. 2 shows a good agreement between the observed tsunami height $\left(h_{0}\right)$ from TTJS group and the simulated tsunami height $\left(h_{s}\right)$ from numerical simulation. For comparison between $h_{o}$ and $h_{s}$ in Table 1, the simulated tsunami height in case of ports without breakwaters is generally higher than the surveyed data of the observed tsunami height for most of ports, except for Miyako (Sokei), Oura, Ogihama, and Momoura. The observed height of Oura, Ogihama, and Momoura is even higher than tsunami height at breakwater ${ }^{3)}$ which might occur due to reflection wave. In addition, based on past studies, tsunami simulations with and without breakwaters revealed that breakwaters did not noticeably reduce water level in the port area because tsunami entered through opening of breakwaters and filled the port basin within a short time ${ }^{8}$.

Fig. 3 and Fig. 4 show linear regression analysis resulting in two linear equations of estimated fatality ratio from tsunami height in case of ports without breakwaters and ports equipped with breakwaters, respectively. It was found that the linear estimated fatality ratio in Fig. 4 is less than that in Fig. 3 approximately $30 \%$ calculated from the slope values of those two linear equations. For the overall image, breakwaters could reduce fatality ratio of people in the port area with a percentage of reduction approximately $30 \%$; nevertheless, it depends on tsunami heights $\left(h_{o}\right.$ and $\left.h_{s}\right)$. Considering the effect of breakwaters at each port, the differences $(\Delta \mathrm{FR})$ between the estimated fatality ratio in case of ports without breakwaters and the surveyed data of fatality ratio (FR) are shown in Table 1. Most of them provided a reduction of fatality ratio (Remark + ), wheras Miyako (Kuwasaki), Kamishi, Oura, Momoura, and Watanoha did not (Remark -). Although the simulated tsunami height $\left(h_{s}\right)$ is less than the observed tsunami height $\left(\mathrm{h}_{\mathrm{o}}\right)$ for Miyako (Sokei) and Ogihama, it still could provide the reduction of fatality ratio.

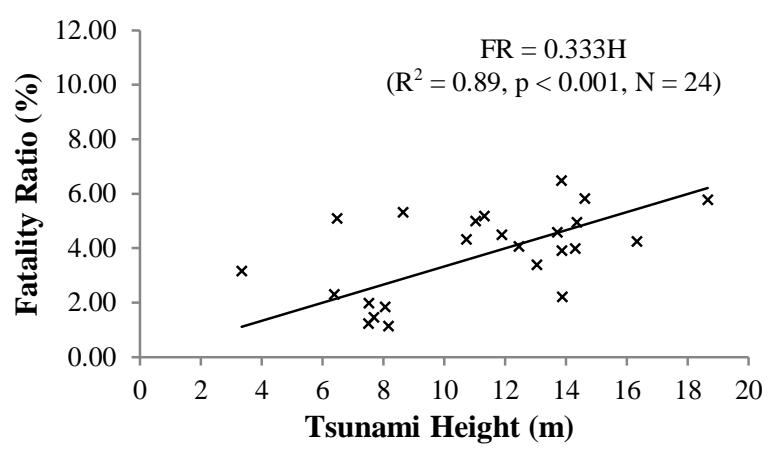

Fig.4 Linear regression analyis from 24 ports equipped with breakwaters. 
Table 1 Tsunami height and fatality data of 24 ports equipped with breakwaters.

\begin{tabular}{|lccccc|}
\hline \multicolumn{1}{|c}{ Port } & $\begin{array}{c}\mathbf{h}_{\mathbf{c}} \\
(\mathbf{m})\end{array}$ & $\begin{array}{c}\mathbf{h} \text { (m) } \\
\text { 1) Taro }\end{array}$ & $\mathbf{F R}$ & $\mathbf{\Delta F R}$ & Remark \\
2) Kuwasaki & 6.49 & 14.32 & $3.92 \%$ & $2.89 \%$ & + \\
3) Sokei & 8.17 & 6.57 & $5.08 \%$ & $-1.73 \%$ & - \\
4) Koyadori & 18.66 & 19.95 & $5.77 \%$ & $1.98 \%$ & + \\
5) Funakoshi & 13.84 & 14.37 & $6.48 \%$ & $0.35 \%$ & + \\
6) Otsuchi & 11.03 & 11.53 & $5.01 \%$ & $0.48 \%$ & + \\
7) Hakozaki & 14.35 & 15.31 & $4.96 \%$ & $2.32 \%$ & + \\
8) Ryoishi & 16.33 & 16.83 & $4.25 \%$ & $3.75 \%$ & + \\
9) Kamaishi & 8.64 & 8.79 & $5.32 \%$ & $-1.14 \%$ & - \\
10) Osabe & 13.71 & 13.78 & $4.59 \%$ & $1.96 \%$ & + \\
11) Wakinosawa & 13.88 & 14.15 & $2.22 \%$ & $4.51 \%$ & + \\
12) Shizugawa & 14.30 & 14.56 & $3.99 \%$ & $2.94 \%$ & + \\
13) Mitobe & 14.62 & 15.49 & $5.83 \%$ & $1.54 \%$ & + \\
14) Aikawa & 11.89 & 12.61 & $4.49 \%$ & $1.50 \%$ & + \\
15) Funakoshi & 12.45 & 12.53 & $4.06 \%$ & $1.90 \%$ & + \\
16) Oura & 11.31 & 9.65 & $5.19 \%$ & $-0.60 \%$ & - \\
17) Onagawa & 13.04 & 13.55 & $3.40 \%$ & $3.04 \%$ & + \\
18) Ayukawa & 7.51 & 7.67 & $1.23 \%$ & $2.42 \%$ & + \\
19) Kobuchihama & 7.52 & 7.87 & $1.99 \%$ & $1.75 \%$ & + \\
20) Fukiura & 7.69 & 8.04 & $1.46 \%$ & $2.36 \%$ & + \\
21) Ogihama & 8.05 & 7.70 & $1.84 \%$ & $1.82 \%$ & + \\
22) Momoura & 10.72 & 8.94 & $4.32 \%$ & $-0.07 \%$ & - \\
23) Watanoha & 3.34 & 3.82 & $3.16 \%$ & $-1.34 \%$ & - \\
24) Ishinomaki & 6.38 & 6.60 & $2.31 \%$ & $0.83 \%$ & + \\
\hline
\end{tabular}

In addition, it was found that fatality ratio of 24 ports has no relationship with breakwater dimension and damage ${ }^{3)}$.

\section{(2) Additional results}

In order to improve accuracy of the investigation, Fig. 5 shows linear regression analysis from the surveyed data of 22 ports having no breakwaters. These data and analysis provided a more realistic linear equations of estimated fatality ratio from tsunami height in case of ports without breakwaters. The observed and simulated tsunami heights $\left(h_{o}\right.$ and $\left.h_{s}\right)$, total number of people $(\mathrm{N})$, number of fatality (D), and fatality ratio (FR) are shown in Table 2 . The estimated fatality ratio in case of ports without breakwaters was calculated by means of the simulated tsunami height and the linear equation in Fig. 5.

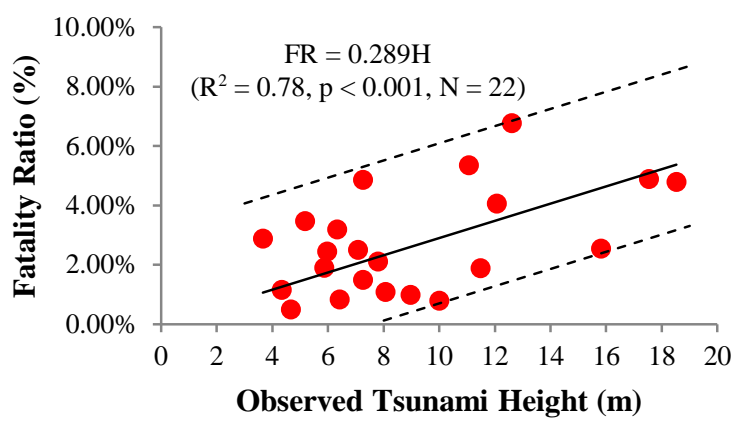

Fig.5 Linear regression analyis from 22 ports having no breakwaters.
In addition to 24 ports equipped with breakwaters in Table 1, the surveyed data of 18 additional ports was conducted to develop a relationship between fatality ratio and tsunami height shown in in Fig. 6. The differences $(\Delta \mathrm{FR})$ between the estimated fatality ratio and the surveyed data of fatality ratio (FR) at each port are shown in Table 3.

Table 2 Tsunami height and fatality data of 22 ports having no breakwaters.

\begin{tabular}{|lccccc|}
\hline \multicolumn{1}{|c}{ Port } & $\begin{array}{c}\mathbf{h}_{\mathbf{c}} \\
(\mathbf{m})\end{array}$ & $\begin{array}{c}\mathbf{h}_{\mathbf{s}} \\
\mathbf{( \mathbf { m } )}\end{array}$ & $\mathbf{N}$ & $\mathbf{D}$ & $\mathbf{F R}$ \\
\hline 1) Yamaguchi & 10.00 & 10.55 & 251 & 2 & $0.80 \%$ \\
2) Yoneaaki & 15.82 & 16.22 & 472 & 12 & $2.54 \%$ \\
3) Asane & 4.66 & 4.27 & 198 & 1 & $0.51 \%$ \\
4) Sakanamachi & 5.97 & 5.65 & 449 & 11 & $2.45 \%$ \\
5) Minatomachi & 5.17 & 4.98 & 115 & 4 & $3.48 \%$ \\
6) Akaiwaminato & 7.25 & 7.02 & 247 & 12 & $4.86 \%$ \\
7) Uoichibamae & 6.33 & 5.54 & 188 & 6 & $3.19 \%$ \\
8) Matsuzakikitasawa & 7.25 & 7.02 & 201 & 3 & $1.49 \%$ \\
9) Matsuzakimaehama & 8.97 & 8.03 & 301 & 3 & $1.00 \%$ \\
10) Saichikawara & 7.80 & 7.53 & 142 & 3 & $2.11 \%$ \\
11) Nagaisofunahara & 6.41 & 6.97 & 2498 & 21 & $0.84 \%$ \\
12) Hajikamiakedo & 12.61 & 9.77 & 118 & 8 & $6.78 \%$ \\
13) Okinoda & 11.48 & 11.56 & 53 & 1 & $1.89 \%$ \\
14) Shirahama & 11.06 & 11.39 & 3718 & 199 & $5.35 \%$ \\
15) Myojin & 12.06 & 11.51 & 3994 & 162 & $4.06 \%$ \\
16) Oyagawahama & 17.53 & 17.30 & 245 & 12 & $4.90 \%$ \\
17) Yagawahama & 18.53 & 18.23 & 167 & 8 & $4.79 \%$ \\
18) Kugunarihama & 5.86 & 6.13 & 262 & 5 & $1.91 \%$ \\
19) Oharahama & 8.07 & 8.78 & 184 & 2 & $1.09 \%$ \\
20) Sato & 4.33 & 4.75 & 950 & 11 & $1.16 \%$ \\
21) Shintona & 3.66 & 3.48 & 243 & 7 & $2.88 \%$ \\
22) Arahama & 7.08 & 7.09 & 479 & 12 & $2.51 \%$ \\
\hline
\end{tabular}

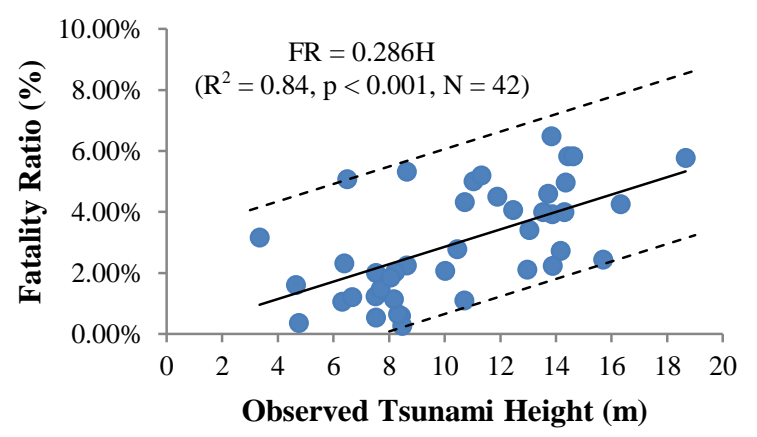

Fig.6 Linear regression analyis from 42 ports equipped with breakwaters.

For the overall image, it was found that breakwaters could reduce fatality ratio of people only $1 \%$, which is much lower than the reduction in the preliminary result, but more accurate. The boundary lines of the scattered points (dashed lines) in Fig. 5 and Fig. 6 are similar as same as the proportion of these scattered points over and under the linear lines. Considering the effect of breakwaters at each port, the differences $(\Delta \mathrm{FR})$ between the estimated fatality ratio in case of ports without breakwaters and the surveyed data of fatality ratio (FR) are shown in 
Table 3. Two third of them (28 ports) provided a reduction of fatality ratio (Remark + ), whereas one third of them (14 ports) did not (Remark -).

Table 3 Tsunami height and fatality data of 42 ports equipped with breakwaters.

\begin{tabular}{|lccccc|}
\hline \multicolumn{1}{|c}{ Port } & $\begin{array}{c}\mathbf{h}_{\mathbf{o}} \\
(\mathbf{m})\end{array}$ & $\begin{array}{c}\mathbf{( \mathbf { m }} \mathbf{)} \\
\text { 1) Noda }\end{array}$ & $\mathbf{F R}$ & $\mathbf{\Delta F R}$ & Remark \\
2) Fudaimura & 8.47 & 10.04 & $0.58 \%$ & $2.39 \%$ & + \\
3) Omoe & 12.96 & 13.94 & $2.26 \%$ & $3.20 \%$ & + \\
4) Taro & 13.86 & 14.32 & $3.92 \%$ & $2.02 \%$ & + \\
5) Kuwasaki & 6.49 & 7.05 & $5.08 \%$ & $-2.99 \%$ & + \\
6) Sokei & 8.17 & 6.57 & $1.14 \%$ & $0.81 \%$ & - \\
7) Takahama & 4.76 & 5.28 & $0.36 \%$ & $1.12 \%$ & + \\
8) Sakaida & 6.31 & 6.20 & $1.05 \%$ & $0.79 \%$ & + \\
9) Dai13Chiwari & 10.01 & 11.52 & $2.06 \%$ & $1.35 \%$ & + \\
10) Koyadori & 18.66 & 19.95 & $5.77 \%$ & $0.13 \%$ & + \\
11) Funakoshi & 13.84 & 14.37 & $6.48 \%$ & $-2.23 \%$ & - \\
12) Otsuchi & 11.03 & 11.53 & $5.01 \%$ & $-1.59 \%$ & - \\
13) Kirikiri & 14.44 & 13.63 & $5.83 \%$ & $-1.79 \%$ & - \\
14) Hakozaki & 14.35 & 15.31 & $4.96 \%$ & $-0.42 \%$ & - \\
15) Ryoishi & 16.33 & 16.83 & $4.25 \%$ & $0.73 \%$ & + \\
16) Kamaishi Bay & 8.32 & 9.84 & $0.64 \%$ & $2.27 \%$ & + \\
17) Kamaishi & 8.64 & 8.79 & $5.32 \%$ & $-2.72 \%$ & - \\
18) Yunagomae & 7.53 & 8.52 & $0.53 \%$ & $2.00 \%$ & + \\
19) Takonoura & 8.64 & 10.11 & $2.25 \%$ & $0.75 \%$ & + \\
20) Okirai & 10.45 & 11.04 & $2.78 \%$ & $0.49 \%$ & + \\
21) Osabe & 13.71 & 13.78 & $4.59 \%$ & $-0.51 \%$ & - \\
22) Otomo & 14.16 & 15.23 & $2.72 \%$ & $1.79 \%$ & + \\
23) Hirota & 10.70 & 11.62 & $1.09 \%$ & $2.35 \%$ & + \\
24) Wakinosawa & 13.88 & 14.15 & $2.22 \%$ & $1.97 \%$ & + \\
25) Sodehama & 13.53 & 14.24 & $3.99 \%$ & $0.23 \%$ & + \\
26) Shizugawa & 14.30 & 14.56 & $3.99 \%$ & $0.33 \%$ & + \\
27) Mitobe & 14.62 & 15.49 & $5.83 \%$ & $-1.24 \%$ & - \\
28) Aikawa & 11.89 & 12.61 & $4.49 \%$ & $-0.76 \%$ & - \\
29) Funakoshi & 12.45 & 12.53 & $5.83 \%$ & $-1.24 \%$ & - \\
30) Oura & 11.31 & 9.65 & $4.06 \%$ & $-0.35 \%$ & - \\
31) Onagawa & 13.04 & 13.55 & $3.40 \%$ & $0.61 \%$ & + \\
32) Ayukawa & 7.51 & 7.67 & $1.23 \%$ & $1.04 \%$ & + \\
33) Kobuchihama & 7.52 & 7.87 & $1.99 \%$ & $0.34 \%$ & + \\
34) Fukiura & 7.69 & 8.04 & $1.46 \%$ & $0.92 \%$ & + \\
35) Yoriisohama & 15.70 & 12.21 & $2.43 \%$ & $1.18 \%$ & + \\
36) Kitsunezaki & 8.21 & 7.60 & $2.03 \%$ & $0.22 \%$ & + \\
37) Ogihama & 8.05 & 7.70 & $1.84 \%$ & $0.44 \%$ & + \\
38) Momoura & 10.72 & 8.94 & $4.32 \%$ & $-1.68 \%$ & - \\
39) Watanoha & 3.34 & 3.82 & $3.16 \%$ & $-2.03 \%$ & - \\
40) Ishinomaki & 6.38 & 6.60 & $2.31 \%$ & - \\
41) Shiogama & 4.65 & 5.47 & $1.60 \%$ & $0.02 \%$ & - \\
42) Hanabushi & 6.67 & 7.20 & $1.20 \%$ & $0.93 \%$ & + \\
\hline & & & & & + \\
\hline
\end{tabular}

\section{CONCLUSIONS}

Fatality data of people during the 2011 Great East Japan tsunami in Iwate and Miyagi were used to calculate fatality ratio of ports equipped with breakwaters and estimate fatality ratio in case of ports without breakwaters. For preliminary study, the relationship between fatality ratio and tsunami height in 24 fishery ports was developed based on the surveyed data after the 2011 tsunami. In addition, the estimated fatality ratio in case of ports without breakwater was calculated by simulated tsunami height to study the effect of breakwaters on fatality ratio of people living in the port area. The reduction of fatality ratio was examined by the differences between fatality ratio in case ports equipped with and without breakwaters. From the simple assumption, the percentage of reduction was approximately $30 \%$ calculated from the difference of the slope values between two linear equations for the overall image. Focusing on each port, most of ports provided the reduction of fatality ratio. Although the simulated tsunami height is less than the observed tsunami height for some ports, it still could provide the reduction of fatality ratio. However, there are still some limitations that should be concerned for these preliminary results. First, the number of breakwaters used in this study is limited to 24 port locations. Second, the general estimating equation is limited to fatality data of 13 city), not particular in port area having no breakwater. In addition, it was found that fatality ratio of 24 ports has no relationship with breakwater dimension and damage.

Additional study was conducted to improve accuracy of the investigation by adding more 18 ports equipped with breakwaters and comparing with fatality data of 24 ports having no breakwaters. From the more advanced assumption, the percentage of reduction became $1 \%$, which is much lower than the reduction in the preliminary study. Focusing on each port, two third of them provided a reduction of fatality ratio, whereas one third of them did not.

This study suggested that the existence of breakwaters can reduce fatality ratio of people due to the 2011 tsunami for most of ports. The results of loss reduction can support future construction and strengthening of breakwaters, which provide extra benefit apart from fishery, even though most breakwaters are not designed for loss reduction from tsunami. These findings can partially prove a significance of the existence of breakwaters on the reduction of fatality ratio and will be important for disaster mitigation planning against future large tsunami. For further improvement, the parameter of influential factors should not be limited to only tsunami height and nonlinear regression analysis should be performed in the future attempt.

ACKNOWLEDGMENT: The authors would like to thank the 2011 Tohoku Earthquake Tsunami Joint Survey (TTJS) Group for providing the surveyed data of tsunami height. We appreciate the fatality data provided by Reconstruction Assistance Research Archive, University of Tokyo.

This research was funded by the Willis Research Network (WRN) under the Pan-Asian/Oceanian tsunami risk modeling through the International Research Institute of Disaster Science (IRIDeS) at Tohoku University. 


\section{APPENDIX A}

Table 4 Location and fatality data of 24 ports equipped with breakwaters.

\begin{tabular}{|lcccc|}
\hline \multicolumn{1}{|c}{ Port } & Lat & Long & N & D \\
\hline 1) Taro & 39.73269167 & 141.9748222 & 3062 & 120 \\
2) Kuwasaki & 39.64166944 & 141.9747528 & 197 & 10 \\
3) Sokei & 39.62810556 & 141.9721940 & 263 & 3 \\
4) Koyadori & 39.42526670 & 142.0132806 & 381 & 22 \\
5) Funakoshi & 39.42449722 & 141.9782611 & 694 & 45 \\
6) Otsuchi & 39.34927778 & 141.9323361 & 799 & 40 \\
7) Hakozaki & 39.32566111 & 141.9143250 & 1311 & 65 \\
8) Ryoishi & 39.30491667 & 141.8941083 & 636 & 27 \\
9) Kamaishi & 39.27065000 & 141.9040806 & 188 & 10 \\
10) Osabe & 38.99316111 & 141.2595560 & 566 & 26 \\
11) Wakinosawa & 39.00454167 & 141.6577139 & 225 & 5 \\
12) Shizugawa & 38.67291944 & 141.4502222 & 8180 & 326 \\
13) Mitobe & 38.64336944 & 141.4607389 & 2350 & 137 \\
14) Aikawa & 38.60229167 & 141.5024500 & 3896 & 175 \\
15) Funakoshi & 38.53505833 & 141.5088639 & 3994 & 162 \\
16) Oura & 38.45463611 & 141.4954111 & 231 & 12 \\
17) Onagawa & 38.40266389 & 141.5047972 & 294 & 10 \\
18) Ayukawa & 38.29473056 & 141.5066806 & 1462 & 18 \\
19) Kobuchihama & 38.32439722 & 141.4664444 & 753 & 15 \\
20) Fukiura & 38.35182778 & 141.4467750 & 137 & 2 \\
21) Ogihama & 38.37542500 & 141.4474611 & 163 & 3 \\
22) Momoura & 38.39713889 & 141.4309000 & 185 & 8 \\
23) Watanoha & 38.40719722 & 141.3658444 & 7157 & 226 \\
24) Ishinomaki & 38.40664440 & 141.3315722 & 130 & 3 \\
\hline
\end{tabular}

\section{APPENDIX B}

Table 5 Location and fatality data of additional 20 ports equipped with breakwaters.

\begin{tabular}{|lcccc|}
\hline \multicolumn{1}{c}{ Port } & Lat & Long & N & D \\
\hline 1) Noda & 40.11532220 & 141.83449440 & 4632 & 27 \\
2) Fudaimura & 40.01135556 & 141.90707500 & 3088 & 8 \\
3) Omoe & 39.57582100 & 142.03014300 & 1186 & 25 \\
4) Takahama & 39.60144400 & 141.95239900 & 841 & 3 \\
5) Sakaida & 39.46223400 & 141.95739800 & 410 & 37 \\
6) Dai13Chiwari & 39.41873100 & 141.98358700 & 97 & 2 \\
7) Kirikiri & 39.37278400 & 141.94662900 & 635 & 37 \\
8) Kamaishi Bay & 39.25794722 & 141.93086110 & 3751 & 24 \\
9) Yunagomae & 39.03667800 & 141.72240200 & 568 & 3 \\
10) Takonoura & 39.03590300 & 141.73668200 & 267 & 6 \\
11) Okirai & 39.11335600 & 141.81825600 & 288 & 8 \\
12) Otomo & 38.98311700 & 141.70988600 & 1911 & 52 \\
13) Hirota & 38.95372300 & 141.68988800 & 457 & 5 \\
14) Sodehama & 38.67312800 & 141.46552100 & 8180 & 326 \\
15) Yoriisohama & 38.38842100 & 141.52485700 & 411 & 10 \\
16) Kitsunezaki & 38.34957222 & 141.41880830 & 148 & 3 \\
17) Shiogama & 38.26643889 & 141.05140280 & 2813 & 45 \\
18) Hanabushi & 38.30608600 & 141.08245100 & 416 & 5 \\
\hline
\end{tabular}

\section{REFERENCES}

1) Suppasri, A., Koshimura, S., Imai, K., Mas, E., Gokon, H., Muhari, A., and Imamura, F. : Damage characteristic and field survey of the 2011 Great East tsunami in Miyagi prefecture, Coastal Engineering Journal, Vol. 54, No. 1, pp. 125005, 2012.

2) Yun, N. Y. and Hamada, M. : Evacuation behavior and fatality rate of residents during the 2011 great east japan earthquake and tsunami, Earthquake Spectra, Vol. 31, No. 3, pp.1237-1265, 2015.

3) Takagi, H. : Method for quick assessment of Caisson breakwater failure due to tsunamis: retrospective analysis of data from the 2011 Great East Japan earthquake and tsunami, Coastal Engineering Journal, Vol. 57, No. 3, pp. $1550012,2015$.

4) Okada, Y. : Surface deformation due to shear and tensile faults in a half-space, Bull. Seismol. Soc. Am., Vol. 75, pp. 1135-1154, 1985.

5) Satake, K., Fujii, Y., Harada, T. and Namegaya Y. : Time and space distribution of coseismic slip of the 2011 Tohoku earthquake as inferred from tsunami waveform data, Bull. Seismol. Soc. Am., 2013.

6) Tani, K. : Distribution of the number of deaths and the death rate on the Great East Japan earthquake (in Japanese), Geography research report, Faculty of Education, Saitama University, 2012.

7) The 2011 Tohoku Earthquake Tsunami Joint Survey Group : Nationwide Field Survey of the 2011 Off the Pacific Coast of Tohoku Earthquake Tsunami, Journal of Japan Society of Civil Engineers, Series B, Vol. 67, No.1, pp.63-66, 2011.

8) Takagi, H. and Bricker, J. : Assessment of the effectiveness of general breakwaters in reducing tsunami inundation in Ishinomaki, Coastal Engineering Journal, Vol. 56, No. 4, pp. 21, 2014.

9) Suppasri, A., Muhari, A., Futami, T., Imamura, F. and Shuto, N. : Loss functions of small marine vessels based on surveyed data and numerical simulation of the 2011 Great East Japan tsunami, Journal of Waterway, Port, Coastal and Ocean Engineering-ASCE, Vol. 140, No. 5, pp. 04014018, 2014.

10) Muhari, A., Imamura, F., Suppasri, A. and Mas, E. : Tsunami arrival time characteristics of the 2011 Great East Japan tsunami revealed from eyewitness, evidences and numerical simulation, Journal of Natural Disaster Science, Vol. 34, No. 1, pp. 91-104, 2012.

(Received March 16, 2016) 